\title{
Clinical utility and tolerability of linagliptin in diabetic patients
}

\author{
This article was published in the following Dove Press journal: \\ Drug, Healthcare and Patient Safety \\ 21 March 2013 \\ Number of times this article has been viewed
}

\author{
Lauralee Gordon Maxwell' \\ M Shawn McFarland ${ }^{1,2}$ \\ 'Department of Veterans Affairs, \\ TN Valley Healthcare System, \\ Murfreesboro, ${ }^{2}$ The University of \\ Tennessee Department of Clinical \\ Pharmacy, Memphis, TN, USA
}

Background: The purpose of this paper is to review the efficacy, safety, and tolerability of linagliptin in the management of hyperglycemia in adults with type 2 diabetes mellitus.

Methods: A Medline search was performed using the keywords "linagliptin" and "type 2 diabetes" for articles published September 2010 through July 2012. The literature search was limited by the following criteria: articles' publication in the English language, clinical trials, randomized controlled trials, and research conducted in humans.

Results: A review of the data for linagliptin in the treatment of type 2 diabetes as monotherapy or in combination with other antidiabetic therapies suggests clinical efficacy in terms of reductions in glycosylated hemoglobin, fasting plasma glucose, and postprandial glucose. Most adverse events with linagliptin are considered to be mild to moderate in nature. Although linagliptin therapy may offer a low risk of hypoglycemia, the risk increases when it is used in combination with insulin secretagogues. Linagliptin can generally be considered weight neutral, but a weight increase was observed when linagliptin was used in combination with a thiazolidinedione.

Conclusion: Linagliptin is a once-daily oral medication used for the treatment of type 2 diabetes. The use of linagliptin as monotherapy or in combination with metformin, sulfonylureas, or pioglitazone led to improvement in glycemic control and was well tolerated by most patients.

Keywords: type 2 diabetes, linagliptin, dipeptidyl peptidase-4 inhibitor

\section{Introduction}

Linagliptin (Tradjenta ${ }^{\circledR}$, Boehringer Ingelheim, Ridgefield, CT, USA) is a newly approved medication for the treatment of type 2 diabetes mellitus. ${ }^{1}$ This agent is a potent inhibitor of the serine protease enzyme, dipeptidyl peptidase-4 (DPP-4), which is responsible for rapid degradation of two incretin hormones, glucagon-like-peptide 1 (GLP-1) and glucose insulinotropic polypeptide (GIP). GLP-1 and GIP have distinct physiologic actions in the regulation of glucose that would make their augmentation attractive in the patient with type 2 diabetes due to a propensity to achieve decreased levels of both hormones. ${ }^{2}$

GLP-1 is secreted from intestine endocrine L-cells in response to glucose and is responsible for stimulation of insulin release from the pancreas in a glucose-dependent manner. GLP-1 inhibits the release of glucagon, thereby decreasing hepatic gluconeogenesis and insulin inhibition. GLP-1 decreases gastric emptying, delaying arrival of glucose into the vasculature, and works centrally in the brain by increasing satiety with a decrease in food intake. Lastly, GLP-1 can increase $\beta$-cell mass by decreasing apoptosis and by increasing proliferation and neogenesis of $\beta$-cells. ${ }^{3}$ However, this has only been shown in animal models, with no evidence of this noted in humans
Correspondence: M Shawn McFarland VA Tennessee Valley Healthcare System, Alvin C York Campus, University of Tennessee College of Pharmacy, 3400 Lebanon Pike, Murfreesboro, TN 37129, USA Tel +l 6158676000 extn 24796 Email michael.mcfarland2@va.gov 
as yet. ${ }^{4}$ GIP is secreted from the K-cells of the intestine wall, stimulates insulin secretion from the pancreas, and has been shown to decrease cellular death and increase regeneration of $\beta$-cells. ${ }^{3}$

Linagliptin has been shown to be a potent long-acting DPP-4 inhibitor. An in vitro study showed that linagliptin inhibited DPP-4 with a 50\% inhibition concentration $\left(\mathrm{IC}_{50}\right)$ of about $1 \mathrm{nM}$, compared with sitagliptin (19 nM), alogliptin (24 nM), saxagliptin (50 nM), and vidagliptin (62 nM). ${ }^{5}$ Linagliptin has an elimination half-life of 131 hours, ${ }^{6}$ and achieves steady-state concentrations after three doses of $5 \mathrm{mg}$ daily. ${ }^{1}$ Linagliptin has also been shown to inhibit DPP-4 activity by more than $80 \%$ over 24 hours. ${ }^{6-8}$ The presence of these characteristics allows for once-daily oral dosing. ${ }^{7}$ Linagliptin undergoes primarily hepatic elimination, with approximately $85 \%$ of the drug excreted unchanged in the feces. ${ }^{9}$ Despite having a predominately hepatic route of elimination, the main metabolite is pharmacologically inactive. ${ }^{1}$ The overall pharmacokinetic profile of linagliptin may avoid the need to adjust the dose in patients with renal or hepatic impairment. The recommendations provided by the package insert indicate no dose adjustments are required for renal or hepatic impairment. ${ }^{1}$

Multiple therapies have now been introduced to the market that target the incretin hormone system. Current guidelines recommend that these treatments be considered as part of a "patient-centered approach" and be used as a component of a two-drug or three-drug regimen in conjunction with metformin if a patient does not meet their individualized glycosylated hemoglobin (HbA1c) goal. ${ }^{10}$

\section{Materials and methods}

A Medline search was performed using the keywords "linagliptin", "DPP-4 inhibitor", and "type 2 diabetes" for articles published through July 2012. The literature search was limited by the following criteria: publication in the English language, clinical trials, randomized controlled trials, and research conducted in humans (Figure 1). Here we summarize the available data with a focus on the clinical utility and tolerability of linagliptin.

\section{Results}

\section{Linagliptin monotherapy}

This Phase IIa study conducted by Forst et al followed a randomized, double-blind, within-dose level, parallel, placebocontrolled design and examined the pharmacokinetic and pharmacodynamic properties of linagliptin in patients with type 2 diabetes after 4 weeks of treatment. ${ }^{11}$ Participants enrolled in this study were either treatment-naïve or had received up to two oral antidiabetic therapies other than a thiazolidinedione. Participants were 21-70 (median 62) years of age, had a body mass index of $18.5-35 \mathrm{~kg} / \mathrm{m}^{2}$, and had an $\mathrm{HbA} 1 \mathrm{c} \leq 8.5 \%$ for treatment-naïve and/or one oral antidiabetic therapy, and $\leq 8.0 \%$ for patients treated with two

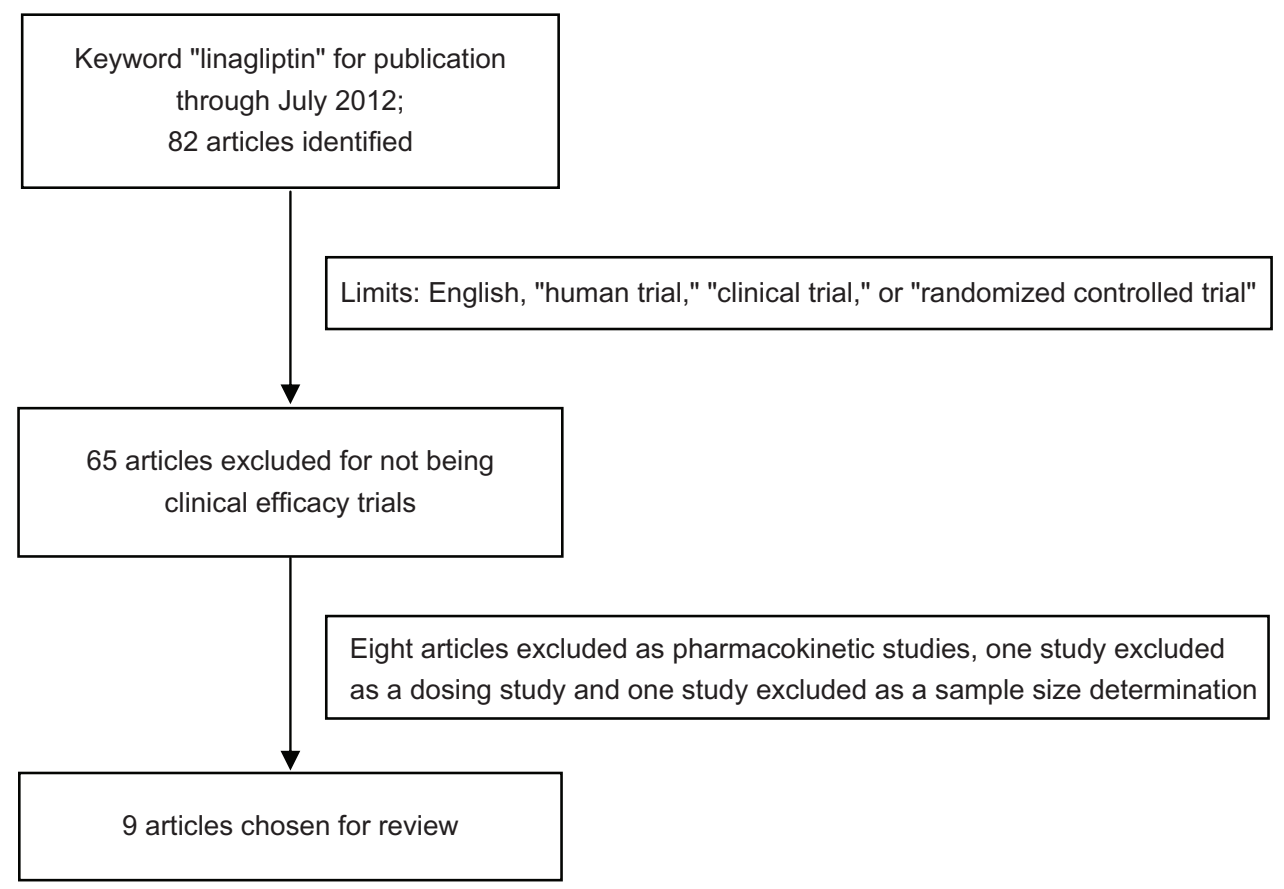

Figure I Flowchart of literature selection. 
oral antidiabetic therapies. The HbA1c for the total cohort of 77 patients was $7.0 \%$. In participants receiving an oral antidiabetic therapy, a washout period of 14 days was required. Eligible patients were randomly assigned to receive linagliptin $2.5 \mathrm{mg}(\mathrm{n}=26), 5 \mathrm{mg}(\mathrm{n}=16), 10 \mathrm{mg}(\mathrm{n}=19)$, or placebo $(n=16)$. Statistically significant decreases in mean HbA1c from baseline were observed at the end of the 4-week period for all the linagliptin groups compared with placebo. The placebo-corrected mean change in $\mathrm{HbA} 1 \mathrm{c}$ was $-0.31 \%$ for linagliptin $2.5 \mathrm{mg},-0.37 \%$ for linagliptin $5 \mathrm{mg}$, and $-0.28 \%$ for linagliptin $10 \mathrm{mg}(P=<0.025)$. Statistically significant decreases in fasting plasma glucose and postprandial plasma glucose were also observed from baseline to the end of the study period for all linagliptin doses (see Table 1).

Another randomized, double-blind, parallel-group study comparing treatment with either linagliptin $5 \mathrm{mg}$ or placebo for 24 weeks in patients with type 2 diabetes was conducted by Del Prato et al. ${ }^{12}$ Patients were aged $18-80$ (mean 55.7) years with a body mass index $\leq 40 \mathrm{~kg} / \mathrm{m}^{2}$, and were either treatment-naïve or previously treated with one oral antidiabetic therapy other than a thiazolidinedione. Pretreated patients underwent a 6-week washout period, with the last 2 weeks being an open-label placebo run-in. Treatment-naïve patients entered directly into the 2 -week placebo run-in period. HbA1c levels had to be between $6.5 \%$ and $9.0 \%$ in non-treatment-naive patients or between $7.0 \%$ and $10 \%$ in treatment-naïve patients. Eligible patients were then randomized to receive treatment with linagliptin $5 \mathrm{mg}$ or placebo for 24 weeks. The adjusted mean difference in the change of $\mathrm{HbA} 1 \mathrm{c}$ comparing linagliptin and placebo was $-0.69 \%$ ( $P<0.0001)$. The primary endpoint was adjusted for baseline $\mathrm{HbA} 1 \mathrm{c}$ and previous oral antidiabetic therapy. Treatment with linagliptin also resulted in significant decreases in fasting plasma glucose and postprandial plasma glucose compared with placebo (see Table 1).

\section{Combination therapy}

Linagliptin versus placebo as add-on therapy to metformin

Taskinen et al performed a randomized, double-blind, placebo-controlled, multicenter, parallel-group study in 701 patients with type 2 diabetes aged $18-80$ years. ${ }^{13}$ Subjects included had a mean age of 56.5 years, a body mass index $\leq$ $40 \mathrm{~kg} / \mathrm{m}^{2}$, and a mean baseline HbA1c of $8.1 \%$. Subjects eligible for inclusion needed to have received metformin at a dose $\geq 1500 \mathrm{mg} /$ day (or the maximum tolerated dose) and not more than one other oral antidiabetic therapy. In patients who had previously been treated with metformin monotherapy, $\mathrm{HbA} 1 \mathrm{c}$ had to be $7.0 \%-10.0 \%$ at screening; for patients treated with an additional medication, A1c had to be $6.5 \%-9.0 \%$. Patients taking antidiabetic therapy in addition to metformin were instructed to stop the medication and then underwent a 6-week washout period that included an openlabel placebo run-in phase in the last 2 weeks. For patients taking metformin monotherapy at enrolment, only the 2-week run-in phase was required. All eligible patients continued their usual dose of metformin and were then randomized to treatment with either linagliptin $5 \mathrm{mg}$ once daily or placebo for 24 weeks. The primary endpoint was the change from baseline $\mathrm{HbA1c}$, adjusted for baseline $\mathrm{HbA1c}$ and the use of monotherapy versus combination therapy at enrolment, after 24 weeks of treatment. At the end of the study, linagliptin reduced the mean $\mathrm{HbA} 1 \mathrm{c}$ level by $0.49 \%$, whereas $\mathrm{HbA} 1 \mathrm{c}$ in the placebo group rose by $0.15 \%(P<0.0001)$. The placebo-corrected reduction in HbAlc was $0.64 \%$. Linagliptin also led to significant reductions versus placebo in both fasting plasma glucose and postprandial plasma glucose $(P<0.0001$, see Table 2$)$.

\section{Linagliptin + metformin versus linagliptin alone, metformin alone, and placebo}

Haak et al conducted a 24-week, randomized, double-blind, placebo-controlled Phase III trial in 791 patients who were either treatment-naïve or had been treated with one other antidiabetic therapy. ${ }^{15}$ Eligible patients were $18-80$ years of age, had a diagnosis of type 2 diabetes, and had a body mass index of $\leq 40 \mathrm{~kg} / \mathrm{m}^{2}$. In treatment-naïve participants, $\mathrm{HbA} 1 \mathrm{c}$ had to be $\geq 7.5 \%$ and $<11 \%$, and for patients pretreated with one antidiabetic therapy had to be $\geq 7.0 \%$ to $\leq 10.5 \%$. Patients pretreated with one antidiabetic therapy entered a 4-week washout period followed by a 2-week placebo run-in period that all patients participated in. Subjects were then treated for 24 weeks with one of two free combinations of linagliptin (linagliptin $2.5 \mathrm{mg}$ twice daily + metformin $500 \mathrm{mg}$ twice daily or $1000 \mathrm{mg}$ twice daily) or placebo, linagliptin $5 \mathrm{mg}$ once daily, metformin $500 \mathrm{mg}$ twice daily, or metformin $1000 \mathrm{mg}$ twice daily monotherapy. The primary endpoint was change in $\mathrm{HbAlc}$ from baseline to 24 weeks of treatment, adjusted for baseline HbAlc and previous oral antidiabetic therapy. Mean baseline HbA1c values were similar for all treatment groups, with an overall mean of $8.7 \%$. The adjusted placebo-corrected mean $(95 \%$ confidence interval) changes in $\mathrm{HbA} 1 \mathrm{c}$ were $-1.7 \%(-2.0 \%$, $-1.4 \%$ ) for linagliptin + metformin $1000 \mathrm{mg} ;-1.3 \%(-1.6$, $-1.1)$ for linagliptin + metformin $500 \mathrm{mg} ;-1.2 \%(-1.5 \%$, $-0.9 \%$ ) for metformin $1000 \mathrm{mg} ;-0.8 \%(-1.0,-0.5)$ for 


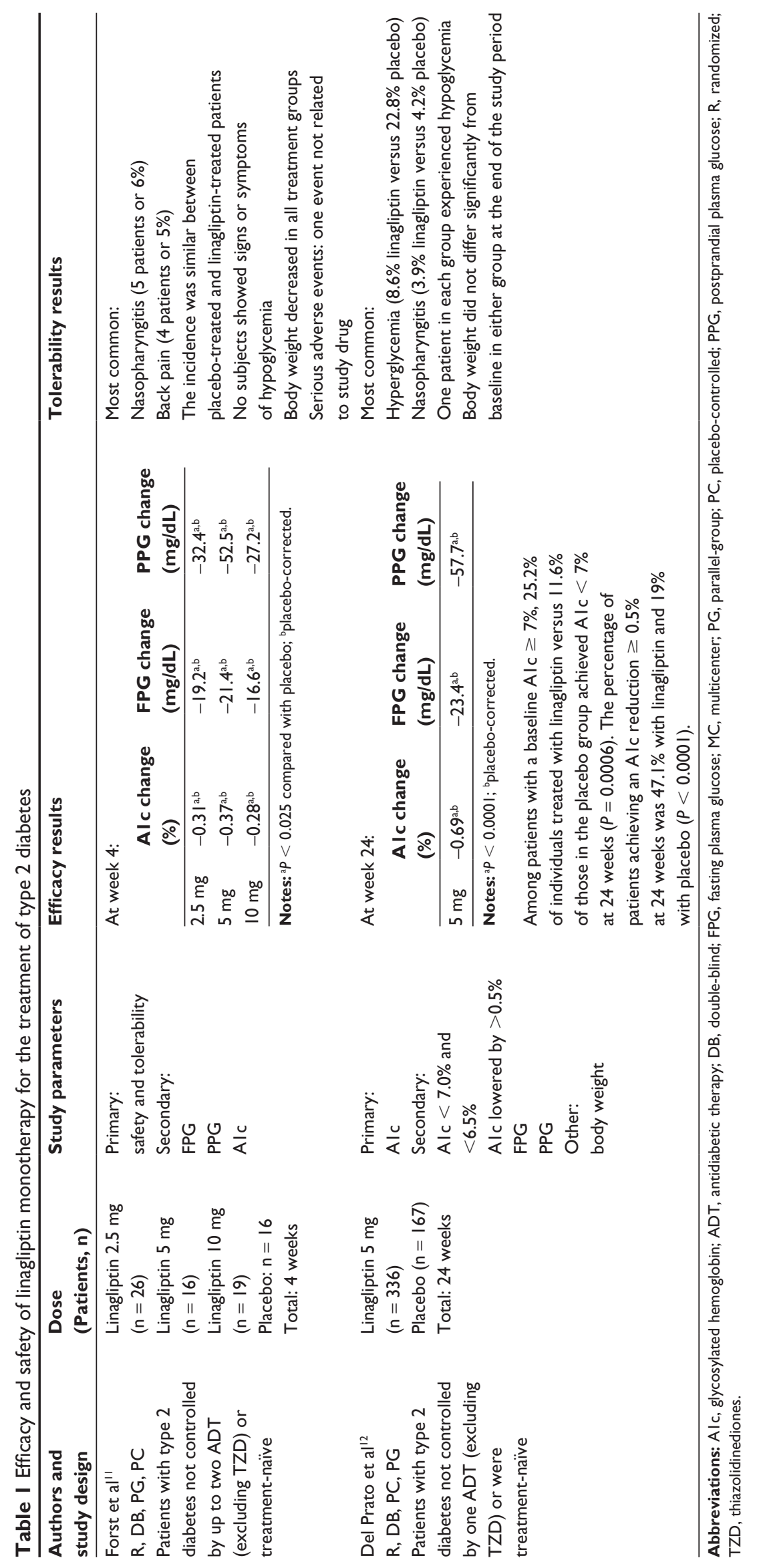


metformin $500 \mathrm{mg}$; and $-0.6 \%(-0.9 \%,-0.3 \%)$ for linagliptin monotherapy (all $P<0.0001$ ). Significant reductions in fasting plasma glucose from baseline to the end of the study period were seen with combination therapies relative to metformin monotherapy. The placebo-corrected changes in fasting plasma glucose from baseline were also statistically significant for each group. This study did not assess changes in postprandial plasma glucose (see Table 2).

\section{Linagliptin versus placebo in combination with metformin and sulfonylurea}

This randomized, placebo-controlled, double-blind, parallelgroup study enrolled subjects with type 2 diabetes receiving metformin $\geq 1500 \mathrm{mg} /$ day (or the maximum tolerated dose) and the maximum tolerated dose of sulfonylurea. ${ }^{16}$ Patients were 18-80 (mean 58.1) years of age, with a body mass index $\leq 40 \mathrm{~kg} / \mathrm{m}^{2}$ and $\mathrm{HbA} 1 \mathrm{c} \geq 7.0 \%$ and $\leq 10.0 \%$ (mean $8.14 \%$ ). Following a 2 -week placebo run-in, a total of 1055 participants were randomized to treatment with linagliptin $5 \mathrm{mg}$ once daily or placebo, in addition to the established background therapy of metformin in combination with a sulfonylurea. The primary endpoint was the change in $\mathrm{HbA} 1 \mathrm{c}$ levels between baseline and 24 weeks, stratified by baseline $\mathrm{HbA} 1 \mathrm{c}$ value. After 24 weeks, linagliptin was superior to placebo for the adjusted mean change in $\mathrm{HbA} 1 \mathrm{c}$ from baseline. The linagliptin placebo-corrected adjusted mean change from baseline was $-0.62 \%(P<0.0001)$. Linagliptin also produced greater reductions in fasting plasma glucose than placebo at week 24 ( $P<0.0001$, see Table 2$)$.

\section{Linagliptin versus glimepiride in combination with metformin}

This randomized, double-blind, parallel-group, active-controlled, noninferiority trial was conducted by Gallwitz et al in 1519 patients with type 2 diabetes, aged $18-80$ years, and a body mass index of $\leq 40 \mathrm{~kg} / \mathrm{m}^{2} \cdot{ }^{17}$ Eligible subjects were receiving metformin $1500 \mathrm{mg} /$ day (or the maximum tolerated dose) alone with an $\mathrm{HbA} 1 \mathrm{c}$ of $6.5 \%-10.0 \%$ or $6.0 \%-9.0 \%$ on metformin and one other oral antidiabetic therapy. Mean baseline $\mathrm{HbA1c}$ and age were $7.7 \%$ and 59.8 years in each group, respectively. Participants receiving metformin and one additional antidiabetic therapy entered a 6-week washout period followed by a 2 -week open-label placebo run-in. Those receiving metformin monotherapy entered directly into a 2-week, open-label, placebo run-in period. Subjects who met the inclusion criteria were then randomly assigned to treatment with linagliptin $5 \mathrm{mg}$ once daily or glimepiride at an initial dose of $1 \mathrm{mg}$ daily added to the current dose of metformin. The primary endpoint was the change in HbAlc from baseline to week 104, and was stratified by baseline $\mathrm{HbA} 1 \mathrm{c}$ and previous antidiabetic therapy use. After 2 years of treatment, linagliptin was noninferior to glimepiride in reducing $\mathrm{HbA} 1 \mathrm{c}$. Adjusted mean changes were $-0.16 \%$ with linagliptin and $-0.36 \%$ with glimepiride. The difference between the treatment groups met the noninferiority criteria and was $0.20 \%(P<0.125)$. As add-on to metformin, both linagliptin and glimepiride caused significant reductions in fasting plasma glucose and postprandial plasma glucose. The treatment differences for reductions in fasting and postprandial plasma glucose, respectively, were $6.31 \mathrm{mg} / \mathrm{dL}$ $(P=0.012)$ and $9.73 \mathrm{mg} / \mathrm{dL}(P=0.0918$, see Table 2$)$.

The 12-week, multicenter, randomized, double-blind, placebo-controlled, five parallel-group study conducted by Forst et al included patients with type 2 diabetes aged $21-75$ (mean 60) years with a body mass index of $25-40 \mathrm{~kg} / \mathrm{m}^{2} .{ }^{14}$ Patients were eligible if they were pretreated with metformin alone (baseline HbA1c levels had to be $7.5 \%-10 \%$ ) or treated with metformin and one other oral antidiabetic therapy other than a thiazolidinedione (baseline HbAlc levels had to be 7.0\%-9.0\%). Eligible patients who had already received metformin monotherapy entered a 2-week open-label runin phase. Patients who received metformin plus one other antidiabetic therapy entered a 6-week washout period, with the last 2 weeks being an open-label run-in phase. Three doses of linagliptin $(1,5$, and $10 \mathrm{mg}$ once daily) were explored when added to metformin. There was also an open-label treatment arm where patients were randomized to receive glimepiride (1, 2, or $3 \mathrm{mg}$ once daily) as add-on therapy to metformin. The mean placebo-corrected lowering of $\mathrm{HbA} 1 \mathrm{c}$ levels was $0.39 \%$ for linagliptin $1 \mathrm{mg}(P=0.005), 0.75 \%$ for $5 \mathrm{mg}(P<0.001)$, and $0.73 \%$ for $10 \mathrm{mg}(P<0.001)$. The change in mean placebo-corrected HbA1c from baseline was $-0.90 \%$ for glimepiride. The reduction in $\mathrm{HbA} 1 \mathrm{c}$ with open-label glimepiride was numerically greater versus linagliptin, but not statistically significant. Fasting plasma glucose reductions were also found to be significantly greater with all doses of linagliptin than with placebo at week 12 . Postprandial plasma glucose changes were not addressed in this study (see Table 2).

\section{Linagliptin versus placebo as add-on to pioglitazone therapy}

This randomized, double-blind, placebo-controlled, multicenter, parallel-group study was conducted by Gomis et al in 389 patients with type 2 diabetes and aged 18-80 (mean 57.5) years. ${ }^{18}$ At baseline, the patients had HbA1c 
Table 2 Efficacy and safety of linagliptin in combination with other ADTs for the treatment of type 2 diabetes

\begin{tabular}{lll}
\hline $\begin{array}{l}\text { Authors and } \\
\text { study design }\end{array}$ & $\begin{array}{l}\text { Dose, } \\
\text { patients }(\mathbf{n})\end{array}$ & Study parameters \\
\hline Taskinen et al ${ }^{13}$ & Linagliptin $5 \mathrm{mg}(\mathrm{n}=524)+$ metformin & Primary: \\
R, DB, PC, PG & Placebo $(\mathrm{n}=177)+$ metformin & Alc \\
Patients with uncontrolled type 2 & Total: 24 weeks & Secondary: \\
diabetes receiving maximum tolerated & & Body weight \\
dose metformin and not more than one & & FPG \\
other ADT & & PPG \\
& & Alc $<7.0 \%$ and $<6.5 \%$ \\
& Alc lowered by $>0.5 \%$
\end{tabular}

Forst et al' ${ }^{14}$

R, DB, PC, PG

Patients with type 2 diabetes not controlled on metformin alone or with metformin and one other ADT (except TZD)

Haak et $\mathrm{al}^{15}$

R, PC, DB, PG

Patients with type 2 diabetes not controlled who were either treatment-naïv or had been treated with one other ADT

Owens et al ${ }^{16}$

R, PC, DB, PG

Patients with type 2 diabetes not controlled with metformin plus a sulfonylurea
Linagliptin I mg $(n=65)+$ metformin

Linagliptin $5 \mathrm{mg}(\mathrm{n}=66)+$ metformin

Linagliptin $10 \mathrm{mg}(\mathrm{n}=66)+$ metformin

Glimepiride $(n=65)+$ metformin

Placebo $(n=71)+$ metformin

Total: 12 weeks
Primary:

Alc

Secondary:

FPG

Alc $<7.0 \%$

Alc lowered by $>0.5 \%$

Body weight
Linagliptin $2.5 \mathrm{mg}$ BID + metformin $500 \mathrm{mg}$ BID $(n=143)$

Linagliptin $2.5 \mathrm{mg}$ BID + metformin $1000 \mathrm{mg}$ BID $(n=143)$

Linagliptin $5 \mathrm{mg}$ daily $(\mathrm{n}=142)$

Metformin $500 \mathrm{mg}$ BID $(n=144)$

Metformin $1000 \mathrm{mg}$ BID $(\mathrm{n}=147)$

Placebo $(n=72)$

Total: 24 weeks
Primary:

Alc

Secondary:

FPG

Body weight
Linagliptin $5 \mathrm{mg}$ daily + metformin + sulfonylurea $(\mathrm{n}=792)$

Placebo + metformin + sulfonylurea $(n=263)$

Total: 24 weeks
Primary:

Alc

Secondary:

FPG

Alc $<7.0 \%$

Alc lowered by $>0.5 \%$

Body weight 


\section{Efficacy results}

At week 24:

\begin{tabular}{llll} 
& $\begin{array}{l}\text { Alc change } \\
(\%)\end{array}$ & $\begin{array}{l}\text { FPG change } \\
(\mathbf{m g} / \mathbf{d L})\end{array}$ & $\begin{array}{l}\text { PPG change } \\
(\mathbf{m g} / \mathbf{d L})\end{array}$ \\
\hline Linagliptin $5 \mathrm{mg}$ & $-0.64^{\mathrm{a}, \mathrm{b}}$ & $-21.62^{\mathrm{a}, \mathrm{b}}$ & $-66.7^{\mathrm{a}, \mathrm{b}}$ \\
\hline
\end{tabular}

Notes: $\mathrm{p} p<0.000$; ${ }^{\text {b}}$ placebo-corrected.

Among patients with a baseline Alc $\geq 7 \%, 26 \%$ of individuals treated with linagliptin versus $9 \%$ of those in the placebo group achieved Alc $<7 \%$ at 24 weeks $(P=0.000 \mathrm{I})$. Similarly, in those patients with a baseline $\mathrm{HbAlc} \geq 6.5 \%, 10 \%$ with linagliptin versus $2 \%$ with placebo achieved Alc $<6.5 \%$ at 24 weeks $(P=0.0016)$.

The percentage of patients achieving an Alc reduction $\geq 0.5 \%$ at 24 weeks was $50 \%$ with linagliptin and $22 \%$ with placebo $(P<0.000 \mathrm{I})$.

At week 12:

\begin{tabular}{llll} 
& $\begin{array}{l}\text { Alc change } \\
(\%)\end{array}$ & $\begin{array}{l}\text { FPG change } \\
\text { (mg/dL) }\end{array}$ & $\begin{array}{l}\text { Body weight } \\
\text { change }(\mathbf{k g})\end{array}$ \\
\hline $\mathrm{I} \mathrm{mg}$ & $-0.39^{\mathrm{a}, \mathrm{e}}$ & $-19.8^{\mathrm{d}, \mathrm{e}}$ & -0.15 \\
$5 \mathrm{mg}$ & $-0.75^{\mathrm{b}, \mathrm{e}}$ & $-34.2^{\mathrm{ce}}$ & -0.57 \\
$\mathrm{I0} \mathrm{mg}$ & $-0.73^{\mathrm{b}, \mathrm{e}}$ & $-30.6^{\mathrm{c}, \mathrm{e}}$ & -1.27 \\
Glimepiride & $-0.90^{\mathrm{ce}}$ & $\mathrm{NR}$ & +0.73 \\
\hline
\end{tabular}

Notes: ${ }^{\mathrm{P}} P=0.005 ; \mathrm{b} P<0.001 ; \mathrm{c} P<0.0001 ; \mathrm{d} P=0.002 ;{ }^{\mathrm{e}}$ placebo-corrected.

A greater proportion of patients who received linagliptin (43.8\%-53.2\%) showed reductions in $\mathrm{Alc} \geq 0.5 \%$ versus placebo at $12.9 \%$. Only $1.4 \%$ of patients in the placebo group achieved $\mathrm{Alc} \leq 7 \%$ versus $15 \%-21 \%$ of the patients who received linagliptin therapy.

At week 24:

\begin{tabular}{llll} 
& $\begin{array}{l}\text { Alc change } \\
(\%)\end{array}$ & $\begin{array}{l}\text { FPG change } \\
(\mathbf{m g} / \mathbf{d L})\end{array}$ & $\begin{array}{l}\text { Body weight } \\
\text { change }(\mathbf{k g})\end{array}$ \\
\hline $\begin{array}{l}\text { LIN 2.5 mg + } \\
\text { MET } 1000 \mathrm{mg}\end{array}$ & $-1.7^{\mathrm{a}, \mathrm{b}}$ & $-59.46^{\mathrm{a}, \mathrm{b}}$ & -0.8 \\
LIN 2.5 mg + & $-1.3^{\mathrm{a}, \mathrm{b}}$ & $-43.24^{\mathrm{a}, \mathrm{b}}$ & -0.1 \\
MET $500 \mathrm{mg}$ & & & \\
MET $1000 \mathrm{mg}$ & $-1.2^{\mathrm{a}, \mathrm{b}}$ & $-41.44^{\mathrm{a}, \mathrm{b}}$ & -0.5 \\
MET $500 \mathrm{mg}$ & $-0.8^{\mathrm{a}, \mathrm{b}}$ & $-25.23^{\mathrm{a}, \mathrm{b}}$ & -0.7 \\
Linagliptin & $-0.6^{\mathrm{a}, \mathrm{b}}$ & $-18.02^{\mathrm{a}, \mathrm{b}}$ & +0.2 \\
$5 \mathrm{mg}$ & & & \\
Placebo & $\mathrm{N} / \mathrm{A}$ & $\mathrm{N} / \mathrm{A}$ & -0.7 \\
\hline
\end{tabular}

Notes: aPlacebo-corrected; ${ }^{\mathrm{b} P}<0.0001$.

At week 24:

\begin{tabular}{lll} 
& $\begin{array}{l}\text { Alc change } \\
(\%)\end{array}$ & $\begin{array}{l}\text { FPG change } \\
(\mathbf{m g} / \mathbf{d L})\end{array}$ \\
\hline Linagliptin & $-0.62^{\mathrm{a}, \mathrm{b}}$ & $-12.6 \mathrm{I}^{\mathrm{a}, \mathrm{b}}$ \\
\hline
\end{tabular}

Notes: aPlacebo-corrected; ${ }^{\text {p }}<0.000$ I.

Among patients with a baseline AIc $\geq 7 \%, 29.2 \%$ of individuals treated with linagliptin versus $8.1 \%$ of those in the placebo group achieved Alc $<7 \%$ at 24 weeks $(P<0.000 \mathrm{I})$. The percentage of patients achieving an $\mathrm{Alc}$ reduction $\geq 0.5 \%$ at 24 weeks was $58.2 \%$ with linagliptin and $30.2 \%$ with placebo.

\section{Tolerability results}

\section{Most common:}

Hyperglycemia (5.2\% linagliptin versus $14.7 \%$ placebo) Nasopharyngitis (5.2\% linagliptin versus $5.1 \%$ placebo) Minor hypoglycemia ( $0.6 \%$ linagliptin versus $2.3 \%$ placebo) No major hypoglycemia events

Body weight did not differ significantly from baseline in either group $(-0.5 \mathrm{~kg}$ placebo; $-0.4 \mathrm{~kg}$ linagliptin)

Most common:

Nasopharyngitis (reported in $10 \%, 6 \%, 8 \%, 8 \%, 6 \%$ for placebo, I mg, $5 \mathrm{mg}, 10 \mathrm{mg}$ and glimepiride, respectively) Diarrhea (reported in $4 \%, 2 \%, 3 \%, 3 \%, 5 \%$ for placebo, $1 \mathrm{mg}, 5 \mathrm{mg}, 10 \mathrm{mg}$, and glimepiride respectively) Nausea (reported in $4 \%, 0 \%, 6 \%, 5 \%, 0 \%$ for placebo, $1 \mathrm{mg}$, $5 \mathrm{mg}, 10 \mathrm{mg}$, and glimepiride respectively)

Hypoglycemia was not reported with linagliptin or placebo Hypoglycemia was reported in $4.6 \%$ of patients taking glimepiride

Most common:

Diarrhea (7.7\% in LIN $2.5 \mathrm{mg}+$ metformin $1000 \mathrm{mg}$ BID) Nasopharyngitis (8.4\% in LIN 2.5 mg + MET 500 mg BID) Hypoglycemia:

LIN + HD MET - $0 \%$

$\mathrm{LIN}+\mathrm{MD}$ MET $-3.5 \%$

MET $1000 \mathrm{mg}$ BID $-3.4 \%$

MET $500 \mathrm{mg}$ BID - I.4\%

LIN 5 mg daily - $0 \%$

Placebo $-0 \%$

No pancreatitis reported

No clinically meaningful change in body weight was noted in any of the treatment groups

Most common:

Hypoglycemia (22.7\% linagliptin versus $14.8 \%$ placebo) Severe hypoglycemia occurred in $2.7 \%$ linagliptin versus $4.8 \%$ placebo

Neither group showed significant changes in weight from baseline 
Table 2 (Continued)

\begin{tabular}{|c|c|c|}
\hline $\begin{array}{l}\text { Authors and } \\
\text { study design }\end{array}$ & $\begin{array}{l}\text { Dose, } \\
\text { patients (n) }\end{array}$ & Study parameters \\
\hline Gallwitz et al $^{17}$ & Linagliptin 5 mg daily + metformin $(n=764)$ & Primary: \\
\hline $\mathrm{R}, \mathrm{DB}, \mathrm{PG}, \mathrm{AC}, \mathrm{NI}$ & Glimepiride I-4 mg once daily (initially I mg) + metformin & Alc \\
\hline Patients with type 2 diabetes not controlled & $(n=755)$ & Secondary: \\
\hline on metformin alone or with metformin and & Total: 104 weeks & Hypoglycemic episodes \\
\hline \multirow[t]{5}{*}{ one other ADT } & & Body weight \\
\hline & & FPG \\
\hline & & PPG \\
\hline & & Alc $<7.0 \%$ and $<6.5 \%$ \\
\hline & & Alc lowered by $>0.5 \%$ \\
\hline
\end{tabular}

Gomis et $\mathrm{al}^{18}$

R, PC,DB, PG

Drug-naïve or previously treated

patients with uncontrolled type 2

diabetes
Linagliptin $5 \mathrm{mg}$ daily + pioglitazone $30 \mathrm{mg}$ daily

( $n=259)$

Placebo + pioglitazone 30 daily

$(n=130)$

Total: 24 weeks
Primary:

Alc

Secondary:

FPG

Alc $<7.0 \%$

Alc lowered by $>0.5 \%$
Gomis et al $^{19}$

R, PC, DB,

open-label extension

Trial participants who had

completed one of the four 24-week

parent trials ${ }^{12,13,16,18}$

\author{
Linagliptin monotherapy \\ Linagliptin + metformin \\ Linagliptin + metformin + sulfonylurea \\ Linagliptin + pioglitazone \\ Group A ( $n=1349)$ received linagliptin as monotherapy or \\ combination during previous trials and remained on the \\ same treatment in extension phase \\ Group B $(n=531)$ received placebo during the previous \\ studies and were switched to linagliptin monotherapy \\ in the extension phase \\ Total: 102 weeks (24 weeks with a 78-week, \\ open-label extension)
}

Primary:
Long-term safety and
tolerability of linagliptin given
alone or in combination with
other ADT
Secondary:
Alc
FPG
Alc $<7.0 \%$
Alc lowered by $>0.5 \%$
Body weight

Abbreviations: AC, active controlled; Alc, glycosylated hemoglobin; ADT, antidiabetic therapy; BID, twice daily; BW, body weight; CV, cardiovascular; DB, double-blind; FPG, fasting plasma glucose; GLIM, glimepiride; HD MET, high dose metformin; LIN, linagliptin; MD MET, moderate dose metformin; MET, metformin; MC, multicenter; $\mathrm{NI}$, noninferiority; NR, not reported; PG, parallel-group; PIO, pioglitazone; PC, placebo-controlled; PPG, postprandial plasma glucose; R, randomized; RR, relative risk; $\mathrm{SU}$, sulfonylurea; TZD, thiazolidinediones.

concentrations of $7.5 \%-11.0 \%$ (mean $8.6 \%$ ) and a body mass index $\leq 40 \mathrm{~kg} / \mathrm{m}^{2}$. Patients pretreated with oral antidiabetic therapies underwent a 6-week washout period that included an open-label placebo run-in phase in the last 2 weeks. For treatment-naïve patients, only the 2 -week run-in phase was required. Eligible subjects were then randomized to receive pioglitazone $30 \mathrm{mg}$ once daily and linagliptin $5 \mathrm{mg}$ once daily or pioglitazone $30 \mathrm{mg}$ once daily and placebo for 24 weeks. The primary endpoint was change from baseline $\mathrm{HbAlc}$, adjusted for baseline $\mathrm{HbA} 1 \mathrm{c}$ and 


\section{Efficacy results}

At week 104

\begin{tabular}{llll} 
& $\begin{array}{l}\text { Alc change } \\
(\%)\end{array}$ & $\begin{array}{l}\text { FPG change } \\
(\mathbf{m g} / \mathbf{d L})\end{array}$ & $\begin{array}{l}\text { PPG change } \\
(\mathbf{m g} / \mathbf{d L})\end{array}$ \\
\hline Linagliptin & $-0.16^{\mathrm{a}}$ & $-2.34^{\mathrm{b}}$ & $-28.47^{\mathrm{c}}$ \\
Glimepiride & $-0.36^{\mathrm{a}}$ & $-8.65^{\mathrm{b}}$ & $-18.74^{\mathrm{c}}$ \\
\hline
\end{tabular}

Notes: ${ }^{\mathrm{T}}$ Treatment difference was $0.20 \% ; P=0.0004,<0.0125$ (onesided); 'treatment difference was $6.31 \mathrm{mg} / \mathrm{dL} ; P=0.0012,<0.05$ (twosided); 'treatment difference was $9.73 \mathrm{mg} / \mathrm{dL} ; P=0.0918$.

The treatment difference in the adjusted mean change in Alc from baseline was $0.20 \%$ and met the prespecified noninferiority criterion of $<0.35 \%$ with a one-sided $\alpha=0.0125$.

A total of $30 \%$ of patients achieved an Alc target of $<7 \%$ with linagliptin versus $35 \%$ with glimepiride, while $12 \%$ achieved an $\mathrm{Alc}$ of $<6.5 \%$ with linagliptin versus $16 \%$ with glimepiride $(P<0.000 I)$. The percentage of patients achieving $\geq 0.5 \%$ reduction in AIc was $26 \%$ with linagliptin and $34 \%$ with glimepiride.

At week 24:

\begin{tabular}{llll} 
& $\begin{array}{l}\text { Alc change } \\
(\%)\end{array}$ & $\begin{array}{l}\text { FPG change } \\
(\mathbf{m g} / \mathbf{d L})\end{array}$ & $\begin{array}{l}\text { Body weight } \\
\text { change } \mathbf{( k g )}\end{array}$ \\
\hline Linagliptin & $-1.06^{\mathrm{a}}$ & $-32.43^{\mathrm{b}}$ & $2.3^{\mathrm{c}}$ \\
Placebo & $-0.56^{\mathrm{a}}$ & $-18.02^{\mathrm{b}}$ & $1.2^{\mathrm{c}}$ \\
\hline
\end{tabular}

Notes: ${ }^{\text {TT }}$ Treatment difference was $0.51 \% ; P<0.000$; ${ }^{b}$ treatment difference was $-14.41 \mathrm{mg} / \mathrm{dL} ; P<0.0001$; ctreatment difference was I.I kg; $P=0.014$

A total of $42.9 \%$ of patients achieved an A Ic target of $<7 \%$ with linagliptin versus $30.5 \%$ with placebo $(P=0.005 \mathrm{I})$. The percentage of patients achieving $\geq 0.5 \%$ reduction in $\mathrm{Alc}$ was $75 \%$ with linagliptin and $50.8 \%$ with placebo. At week 102:

\begin{tabular}{ll} 
& Alc change (\%) \\
\hline Group A & $-0.8^{\mathrm{a}}$ \\
Group B & -0.9 \\
LIN monotherapy & -0.5 \\
LIN + MET & -0.7 \\
MET + LIN + SU & -0.7 \\
LIN + PIO & -1.5
\end{tabular}

Note: ${ }^{a}$ Coefficient of durability per 78 weeks,

$0.14 \%(P<0.000$ I, noninferiority $0.3 \%)$.

A total of $42 . \%$ of subjects in group $A$ and $46.1 \%$ of those in group B reached the Alc target of $<7.0 \%$ at week 78 of the extension phase. The percentage of subjects with Alc lowering by $\geq 0.5 \%$ at week 78 was twice that in group $B$ compared with group $A$

(46.9\% versus $17.1 \%$, respectively).
Tolerability results

Most common:

Hypoglycemia (7\% linagliptin vs $36 \%$ glimepiride; $P<0.000$ I) Nasopharyngitis (16\% in both linagliptin and glimepiride) Back pain ( $9 \%$ linagliptin versus $8 \%$ glimepiride) Severe hypoglycemia: one versus 12 patients with linagliptin and glimepiride, respectively

BW: $-1.4 \mathrm{~kg}$ linagliptin versus $+1.3 \mathrm{~kg}$ glimepiride with treatment difference of $-2.7 \mathrm{~kg}(P<0.000 \mathrm{I})$

CV events: 12 (2\%) patients with linagliptin versus 26 (3\%) patients with glimepiride $(R R=0.46, P=0.0213)$

One patient experienced pancreatitis with linagliptin

\section{Most common:}

Weight gain: $2.3 \%$ with linagliptin + pioglitazone versus $0.8 \%$ with pioglitazone + placebo

Hypoglycemia: I.2\% with linagliptin + pioglitazone vs $0 \%$ with pioglitazone + placebo

BW: mean weight increased in both groups; LIN + PIO was lower than placebo + PIO at baseline $(78.3 \mathrm{~kg}$ and $82.7 \mathrm{~kg}$, respectively) and at week $24(80.8 \mathrm{~kg}$ and $84 \mathrm{~kg}$, respectively)

Most common:

Hyperglycemia (24.4\% group A versus $20.5 \%$ group B) Hypoglycemia (LIN + MET + SU I I\%, LIN + MET 2.I\%, LIN monotherapy $0.5 \%$, LIN + PIO 0.2\%)

Severe hypoglycemia: $0.6 \%$ overall No clinically relevant change in body weight observed Pancreatitis: 4 patients in group A $(0.2 \%$ of the overall treatment set experienced pancreatitis) (2 acute cases and 4 chronic cases) baseline antidiabetic therapy, after 24 weeks of treatment. At the end of the study, the adjusted mean change in $\mathrm{HbA} 1 \mathrm{c}$ from baseline for linagliptin plus pioglitazone was $-1.06 \%$ compared with $-0.56 \%$ for placebo plus pioglitazone. The placebo-corrected difference in $\mathrm{HbA} 1 \mathrm{c}$ was $0.51 \%$. Changes in fasting plasma glucose were assessed as a secondary endpoint, showing a significantly greater reduction for linagliptin plus pioglitazone than for placebo plus pioglitazone. Changes in postprandial plasma glucose were not addressed in this study (see Table 2). 
Open-label extension: linagliptin monotherapy or in combination with other oral antidiabetic therapies

A 78-week open-label extension conducted by Gomis et al evaluated participants who had previously completed one of the four 24-week, randomized, double-blind, placebocontrolled parent trials. ${ }^{19}$ These subjects received either linagliptin monotherapy, linagliptin plus metformin, linagliptin plus metformin and sulfonylurea, or linagliptin plus pioglitazone. All patients receiving one of these treatments during a previous trial continued the same treatment for an additional 78 weeks $(\mathrm{n}=1532)$. Those patients previously treated with placebo were switched to linagliptin monotherapy $(\mathrm{n}=589)$. Overall, the cohort of patients had a mean age of 57.7 years and mean baseline HbAlc of $7.5 \%$. This extension study was conducted primarily to assess the long-term safety and tolerability of linagliptin. Secondary efficacy outcomes evaluated the changes in $\mathrm{HbA} 1 \mathrm{c}$ and fasting plasma glucose from baseline to 102 weeks. In participants randomized to treatment with linagliptin in the four previous trials, the mean change from baseline $\mathrm{HbAlc}$ during the initial 24 weeks of treatment was $-0.8 \%$. This was maintained over the 78 weeks of the extension study, with a change from baseline $\mathrm{HbA} 1 \mathrm{c}$ of $-0.8 \%$. The largest observed reduction in $\mathrm{HbA} 1 \mathrm{c}$ from baseline to week 102 was in the group receiving linagliptin plus pioglitazone at $-1.5 \%$. This was followed by those patients receiving metformin and metformin plus a sulfonylurea in combination with linagliptin $(-0.7 \%)$. Lastly, patients receiving linagliptin monotherapy showed a reduction of $0.5 \%$ at week 102. Similarly, fasting plasma glucose values already reduced during the previous trials further decreased during the extension period. In subjects randomized to placebo in the previous trials and switched to linagliptin monotherapy in the extension phase, the change in mean $\mathrm{HbA1c}$ was $-0.90 \%$. Fasting plasma glucose values also decreased from baseline over the study period (see Table 2).

\section{Safety and tolerability}

Most adverse events with linagliptin were considered to be mild to moderate in nature. Adverse reactions that occurred in $\geq 2 \%$ of patients treated with linagliptin included nasopharyngitis, diarrhea, cough, urinary tract infection, and hypertriglyceridemia (in combination with sulfonylurea therapy), hyperlipidemia, and weight increase (in combination with pioglitazone). ${ }^{1}$ Weight changes were reported or addressed in each of the studies above. No significant changes with regard to body weight were found when linagliptin was given as monotherapy. With regard to sulfonylurea therapy, two of the studies revealed an increase in body weight in patients treated with glimepiride versus those receiving linagliptin. ${ }^{14,17}$ However, in a study in which all patients received metformin and sulfonylurea therapy and were then randomized to placebo or linagliptin, no significant changes in body weight were seen. ${ }^{16}$ When patients received pioglitazone and either placebo or linagliptin, both groups showed an increase in body weight from baseline. The amount of weight gain was larger in patients receiving linagliptin, but the mean weight for patients receiving linagliptin was lower than that in patients receiving placebo at baseline. ${ }^{18}$ In general, linagliptin showed a low propensity to cause hypoglycemia. When used as monotherapy, no patients experienced hypoglycemia in the two studies reviewed. ${ }^{11,15}$ One study reviewing linagliptin as monotherapy versus placebo reported hypoglycemia occurring in one patient in each group. ${ }^{12}$ When combined with metformin and sulfonylurea, a higher percentage of patients receiving linagliptin experienced hypoglycemia versus placebo. However, a smaller percentage of patients experienced severe hypoglycemia when compared with placebo. ${ }^{16}$ Three studies discussed or reported the occurrence of pancreatitis. One study reported zero cases ${ }^{15}$ while another study reported one case of pancreatitis in a patient receiving linagliptin. ${ }^{17}$ A 78 -week, open-label extension study, which included 2121 subjects, reported four cases of pancreatitis in patients who had received linagliptin for a total of 102 weeks, with two cases being acute and two chronic. This was an incidence of $0.2 \%$ in the overall treated set. ${ }^{19}$ According to the prescribing information, pancreatitis was reported more often in patients treated with linagliptin (21.9 per 10,000 patient years) versus placebo (eight per 10,000 patient years). ${ }^{1}$ One study prospectively assessed cardiovascular safety for linagliptin versus sulfonylurea (e.g. glimepiride). Major cardiovascular events occurred in $2 \%$ of patients treated with linagliptin and $3 \%$ treated with glimepiride $(P=0.0213)$. This finding was mainly attributable to a significantly lower number of nonfatal strokes with linagliptin compared with glimepiride, without any relation to hypoglycemia. ${ }^{17}$

\section{Discussion}

Data from the clinical trials suggest that linagliptin administered as monotherapy or in combination with other antidiabetic therapies improves $\mathrm{HbA} 1 \mathrm{c}$ and reduces fasting plasma glucose. ${ }^{11-19}$ When used as monotherapy, linagliptin resulted in a placebo-corrected change in $\mathrm{HbA} 1 \mathrm{c}$ ranging from $-0.28 \%$ to $0.69 \%{ }^{11,12}$ When linagliptin was added to metformin or metformin and a sulfonylurea, similar $\mathrm{HbA} 1 \mathrm{c}$ reductions ranging from $0.39 \%$ to $0.75 \%$ were observed. ${ }^{13,14,16}$ When comparing linagliptin with glimepiride as add-on therapy 
to metformin, a numerically greater response was seen with glimepiride, but this was not statistically significant. However, when linagliptin was used in combination with pioglitazone, larger reductions in placebo-corrected $\mathrm{HbA} 1 \mathrm{c}$ of $1.06 \%$ were seen. ${ }^{18}$ Those studies that evaluated the impact of linagliptin therapy on postprandial plasma glucose also reported an improvement. ${ }^{11-13}$ When used as monotherapy, linagliptin decreased postprandial plasma glucose in the range of $27.2-57.7 \mathrm{mg} / \mathrm{dL}$, and when used in combination with metformin, postprandial plasma glucose decreased by $66.7 \mathrm{mg} / \mathrm{dL} .{ }^{11-13}$ With this, the data suggest linagliptin used as monotherapy or in combination with other antidiabetic therapies offers improvement in glycemic control. Specific populations that may particularly benefit from linagliptin therapy should also be considered. In patients experiencing renal impairment precluding the use of metformin, linagliptin may have a niche in managing glycemia because it does not require dose adjustment in renal compromise. Several of the studies discussed in this review stratified the change in $\mathrm{HbA} 1 \mathrm{c}$ according to the baseline value. Reduction in $\mathrm{HbA} 1 \mathrm{c}$ was greater in patients with a baseline $\mathrm{HbA} 1 \mathrm{c}>9 \%$, offering another possible niche for linagliptin therapy.

DPP-4 inhibitors as a class are generally well tolerated. A minimal risk of hypoglycemia when used as monotherapy and lack of weight gain are some of the desirable characteristics of this class of medications. Overall, linagliptin has been shown to be well tolerated, with adverse events similar to others within its class. It is important to note that although linagliptin offers a low risk of hypoglycemia, this risk increases when this agent is combined with secretagogue therapy. Linagliptin used in combination with thiazolidinediones also offers augmentation of weight gain. Pancreatitis is also of concern and is a class effect of DPP-4 inhibitors, although the risk of the condition seems very low with this medication. A longterm safety and efficacy study evaluated linagliptin therapy in over 2000 patients for a total of 102 weeks and found an overall incidence of $0.2 \% .{ }^{19}$ However, recent discussions have noted that the prevalence of pancreatitis among patients with type 2 diabetes is similar to that seen with incretin hormones. A study published in 2009 by Noel et al found that patients with type 2 diabetes had an almost three-fold greater risk of pancreatitis than those patients without diabetes. ${ }^{20}$ This information suggests that there may not be an increased risk of pancreatitis with incretin therapy.

Linagliptin has several differences compared with the other currently available DPP-4 inhibitors. It has a long halflife and undergoes less renal excretion, avoiding the need for dose adjustments in patients with renal impairment. ${ }^{6,9}$
However, to date, there are no head-to-head studies comparing the efficacy of this agent with other DPP-4 inhibitors in its class.

\section{Conclusion}

Linagliptin is a newly approved DPP-4 inhibitor for use as a once-daily oral medication in the treatment of type 2 diabetes. The use of linagliptin as monotherapy or in combination with metformin or pioglitazone led to reductions in $\mathrm{HbA1c}$ and fasting plasma glucose after 12-24 weeks of therapy. This improvement in glycemic control was shown to be maintained for up to 102 weeks. Linagliptin appears to be well tolerated in most patients. It is generally considered to be weight neutral, unless used in combination with a thiazolidinedione, and has a low risk of hypoglycemia.

\section{Disclosure}

The authors have no conflict of interest to disclose with regard to the content of this article.

\section{References}

1. Tradjenta [package insert]. Ridgefield, CT: Boehringer Ingelheim Pharmaceuticals Inc; 2011.

2. Vilsboll T, Krarup T, Deacon CF, et al. Reduced postprandial concentrations of intact biologically active glucagon-like peptide 1 in type 2 diabetic patients. Diabetes. 2001;50:609-613.

3. Baggio L, Druker DJ. Biology of incretins: GLP-1 and GIP. Gastroenterology. 2007;132:2131-2157.

4. Barnett A. DPP-4 inhibitors and their potential role in the management of type 2 diabetes. Int J Clin Pract. 2006;60:1454-1470.

5. Thomas L, Eckhardt M, Langkopf E, Tadayyon M, Himmelsbach F, Mark M. (R)-8-(3-amino-piperidin-1-yl)-7-but-2ynyl-3-methyl-1-(4 methylquinazolin-2-ylmethyl)-3,7-dihydro-purine2,6-dione (BI 1356), a novel xanthine-based dipeptidyl peptidase 4 inhibitor, has a superior potency and longer duration of action compared with other dipeptidyl peptidase-4 inhibitors. J Pharmacol Exp Ther. 2008;325:175-182.

6. Hüttner S, Graefe-Mody EU, Withopf B, Ring A, Dugi KA. Safety, tolerability, pharmacokinetics, and pharmacodynamics of single oral doses of BI 1356, an inhibitor of dipeptidyl peptidase 4, in healthy male volunteers. J Clin Pharmacol. 2008;48:1171-1178.

7. Heise T, Graefe-Mody EU, Hüttner S, Ring A, Trommeshauser D, Dugi KA. Pharmacokinetics, pharmacodynamics and tolerability of multiple oral doses of linagliptin, a dipeptidyl peptidase-4 inhibitor in male type 2 diabetes patients. Diabetes Obes Metab. 2009;11:786-794.

8. Retlich S, Withopf B, Greischel A, Staab A, Jaehde U, Fuchs H. Binding to dipeptidyl peptidase-4 determines the disposition of linagliptin (BI 1356) - investigations in DPP-4 deficient and wildtype rats. Biopharm Drug Dispos. 2009;30:422-436.

9. Blech S, Ludwig-Schwellinger E, Graefe-Mody EU, Withopf B, Wagner K. The metabolism and disposition of the oral dipeptidyl peptidase-4 inhibitor, linagliptin, in humans. Drug Metab Dispos. 2010;38:667-678

10. Izucchi SE, Bergenstal RM, Buse JB, et al. Management of hyperglycemia in type 2 diabetes: a patient-centered approach: position statement of the American Diabetes Association (ADA) and the European Association for the Study of Diabetes (EASD). Diabetes Care. 2012;35:1364-1379 
11. Forst T, Uhlig-Laske B, Ring A, Ritzhaupt A, Graefe-Mody U, Dugi KA. The oral DPP-4 inhibitor linagliptin significantly lowers HbAlc after 4 weeks of treatment in patients with type 2 diabetes mellitus. Diabetes Obes Metab. 2011;13:542-550.

12. Del Prato S, Barnett AH, Huisman H, Neubacher D, Woerle HJ, Dugi KA. Effect of linagliptin monotherapy on glycemic control and markers of $\beta$-cell function in patients with inadequately controlled type 2 diabetes: a randomized controlled trial. Diabetes Obes Metab. 2011;13: 258-267.

13. Taskinen MR, Rosenstock J, Tamminen I, et al. Safety and efficacy of linagliptin as add-on therapy to metformin in patients with type 2 diabetes: a randomized, double-blind, placebo-controlled study. Diabetes Obes Metab. 2010;13:65-74.

14. Forst T, Uhlig-Laske B, Ring A, et al. Linagliptin (BI 1356), a potent and selective DPP-4 inhibitor, is safe and efficacious in combination with metformin in patients with inadequately controlled type 2 diabetes. Diabet Med. 2010;27:1409-1419.

15. Haak T, Meinicke T, Jones R, Weber S, Von Eynatten M, Woerle HJ. Initial combination of linagliptin and metformin improves glycaemic control in type 2 diabetes: a randomized, double-blind, placebocontrolled study. Diabetes Obes Metab. 2012;14:565-574.
16. Owens DR, Swallow R, Dugi KA, Woerle HJ. Efficacy and safety of linagliptin in persons with Type 2 diabetes inadequately controlled by a combination of metformin and sulfonylurea: a 24-week randomized study. Diabet Med. 2011;28:1352-1361.

17. Gallwitz B, Rosenstock J, Rauch T, et al. 2-year efficacy and safety of linagliptin compared with glimepiride in patients with type 2 diabetes inadequately controlled on metformin: a randomized, double-blind, non-inferiority trial. Lancet. 2012;380:475-483.

18. Gomis R, Espadero RM, Jones R, Woerle HJ, Dugi KA. Efficacy and safety of initial combination therapy with linagliptin and pioglitazone in patients with inadequately controlled type 2 diabetes: a randomized, double-blind, placebo-controlled study. Diabetes Obes Metab. 2011;13: 653-661.

19. Gomis R, Owens DR, Taskinen MR, et al. Long-term safety and efficacy of linagliptin as monotherapy or in combination with other oral glucose-lowering agents in 2121 subjects with type 2 diabetes: up to 2 years exposure in 24-week phase III trials followed by a 78-week open-label extension. Int J Clin Pract. 2012;66:731-740.

20. Noel RA, Patterson RE, Braun DK, Bloomgren GL. Increased risk of pancreatitis and biliary disease observed in patients with type 2 diabetes. Diabetes Care. 2009;32:843-838.

\section{Publish your work in this journal}

Drug, Healthcare and Patient Safety is an international, peer-reviewed open-access journal exploring patient safety issues in the healthcare continuum from diagnostic and screening interventions through to treatment, drug therapy and surgery. The journal is characterized by the rapid reporting of reviews, original research, clinical, epidemiological and

\section{Dovepress}

post-marketing surveillance studies, risk management, health literacy and educational programs across all areas of healthcare delivery. The manuscript management system is completely online and includes a very quick and fair peer-review system. Visit http://www.dovepress.com/ testimonials.php to read real quotes from published authors. 